\title{
AC 2007-746: DEVELOPMENT AND IMPLEMENTATION OF A BALANCED SCORECARD FOR ENGINEERING DISTANCE LEARNING PROGRAMS AT VIRGINIA TECH
}

\section{Sasima Thongsamak, Virginia Tech}

Sasima Thongsamak is a Ph.D, student in the Industrial and Systems Engineering Department at Virginia Tech with expected graduation date of June 2007. Her research is to examine the effects of incentives on construction risk perception and risk-taking behavior of people from different cultures. Thongsamak received her MS in Industrial and Systems Engineering from Virginia Tech in 2002; her BS in Industrial Engineering from Chulalongkorn University, Thailand in 2000.

\section{Glenda Scales, Virginia Tech}

Glenda R. Scales, Associate Dean for Distance Learning and Computing, and Director of International Programs, College of Engineering at Virginia Tech. Dr. Scales received her Doctor of Philosophy in Curriculum and Instruction, 1995, Virginia Tech; MS in Applied Behavioral Science, 1992, John Hopkins University; Bachelor of Science in Computer Science, 1985, Old Dominion University.

\section{Cheryl Peed, Virginia Tech}

Cheryl A. Peed, Assistant Director of International and Distance Learning Programs, College of Engineering. Mrs. Peed received her BGS in Education from the University of South Carolina and has 10 years of teaching experience in the public school system. She has worked in the field of engineering for the past 20 years. She has graduate work in Education. 


\title{
Development and Implementation of a Balanced Scorecard for Engineering Distance Learning Programs
}

\begin{abstract}
For more than twenty years, engineering distance learning programs have provided postbaccalaureate education for working engineers and scientists. The programs are offered in various engineering disciplines that include civil engineering, computer science, electrical engineering, and industrial engineering. State of the art technology that includes interactive videoconferencing and online delivery methods are used to deliver classes to students. The programs did not have a performance indicator to help monitor and evaluate its performance. The Office of Distance Learning and Computing (ODLC) took the initiative to develop a balanced scorecard as a tool to monitor and indicate the performance of the programs. The initiative was driven by the continuous improvement process for one of its distance learning programs, the Commonwealth Graduate Engineering Program (CGEP). After successfully developing and implementing a balance scorecard for CGEP, ODLC expanded the balance scorecard to incorporate all its distance learning programs including Master's of Information Technology (MIT) program, National Institute of Aerospace (NIA) program, and School of Biomedical Engineering and Sciences (SBES) program. This paper reviews development, implementation, and maintenance phases of the balance scorecard. Guidelines and lessons learned throughout these processes are presented. The process of selecting a software program to help maintain the balance scorecard is discussed.

\section{Introduction}

Balanced scorecard was first introduced in the early 1990s by Dr. Robert Kaplan of Harvard Business School and Dr. David Norton, a president of a Massachusetts consulting firm. Balanced scorecard is a tool that "translates an organization's mission and strategy into a comprehensive set of performance measures that provides the framework for a strategic measurement and management system". 1 The balanced scorecard has replaced the traditional performance measurements that only concentrate on financial and accounting measures. These traditional measures fail to address many issues that businesses should be concerned with and fail to monitor multiple dimensions of performance. $^{2}$ Traditional measures provide insufficient and distractive reports for managers to use to make decisions. Numerous studies indicate the limitations and ineffectiveness of the traditional financial performance measures. Kaplan and Norton ${ }^{3}$ pointed out that financial measures only focus on the past and are unable to reflect current value-added actions. Financial measures fail to include other critical factors such as customer satisfaction, employee satisfaction, and the quality of products or services. ${ }^{4}$ Financial measures only represent one perspective of an organization's performance and focus only on the short term goal. ${ }^{5}$ On the other hand, the balanced scorecard measures four perspectives of the organizations. The four balanced scorecard perspectives are customers, internal process, learning and growth, and financial. ${ }^{1}$ The balanced scorecard helps translate mission, vision statements, and the organization's strategy which are in words to measurements that help clarify and communicate the direction of the organization to all of its members. ${ }^{6}$
\end{abstract}

\section{The Balanced Scorecard}

Detail of the four balanced scorecard perspectives are presented below: ${ }^{1,3}$

\section{Customer perspective: How do customers see us?}


This perspective captures how companies provide their products and services from the customer's point of view. Satisfying customers is a top priority for businesses. Managers need to transform their customer service missions to measure issues that matter to customers. These measures usually fall into time, quality, performance, service, or cost categories.

\section{Internal perspective: What must we excel at?}

Since internal processes are what drive companies to ensure customer satisfaction, it is important for companies to focus on their internal process performance. Companies need to identify their niche to maintain their competitive edge. Therefore, companies need to determine in what they must excel.

\section{Innovation and learning perspective: Can we continue to improve and create value?}

Companies need to continue improving their performance in order to meet customers' expectations and excel in internal processes. Continuous learning behavior of the organization is important to ensure that the organization is moving forward and remaining competitive in a high competition environment.

\section{Financial perspective: How do we look to shareholders?}

Kaplan and Norton ${ }^{3}$ identified that the "financial performance measures indicate whether the company's strategy, implementation, and execution are contributing to bottom-line improvement". This category usually consists of profitability, growth, and shareholder value. This perspective denotes the traditional performance measures.

\section{Measurement System Development Process}

ODLC used the measurement system development process (MSDP) to develop a balanced scorecard for its distance learning programs. The MSDP consists of 6 main steps and a central process for creating the infrastructure for the measurement system, as shown in Figure 1. Brief explanation of these steps is presented below (adapted from Rentes \& Van Aken, 2000; adapted from Van Aken \& Coleman, 2001), ${ }^{7,8}$

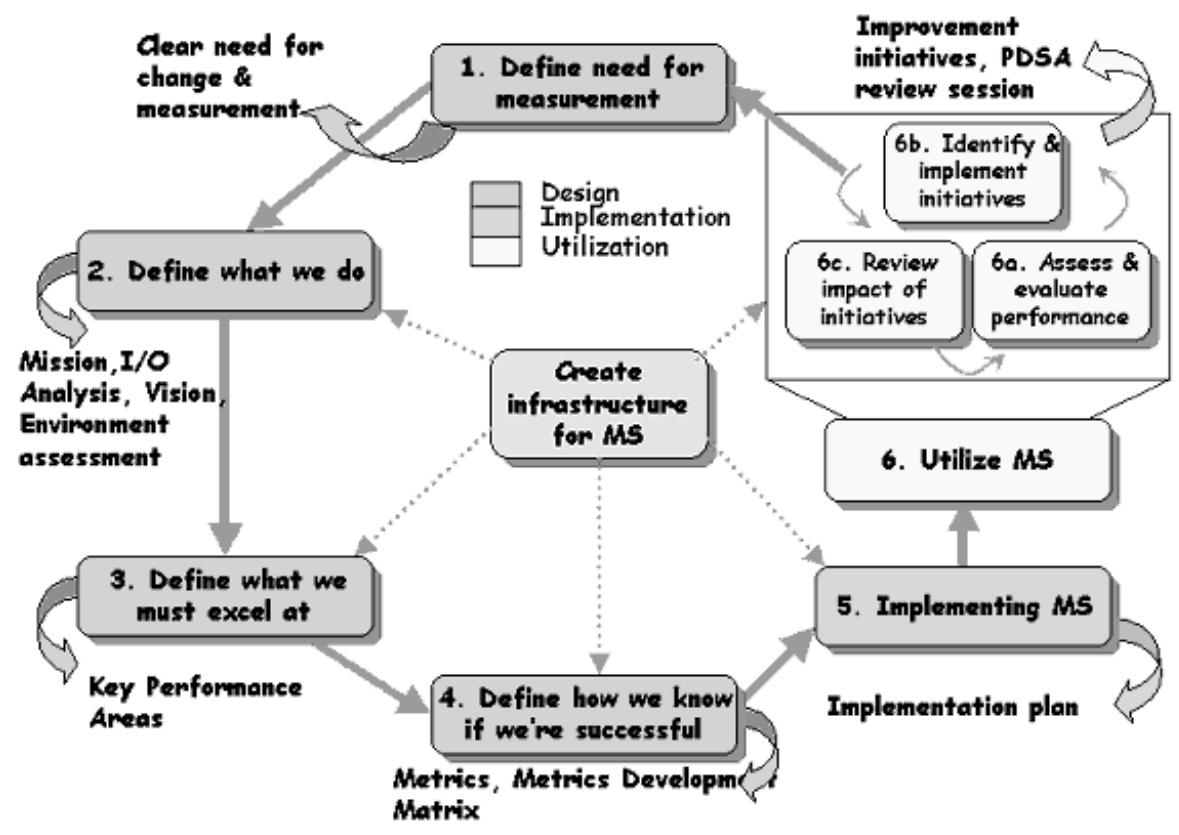

Figure 1: The measurement system development process (MSDP). ${ }^{8}$ 
Create an infrastructure for the measurement system

In this step, the organization needs to create an infrastructure to support the measurement system. This step includes forming a team to design and execute the performance measurement system and developing a communication method between the design team and stakeholders to share information.

\section{Define the need for measurement}

It is important that an organization clearly defines its need for a performance measurement system. A clear purpose will likely lead the organization to successful development and implementation processes for a performance measurement system. Even though a clearly defined purpose cannot guarantee success, it will help the organization rethink whether the performance measurement system is the right solution for the problem.

\section{Define what we do}

In this stage, a target system is defined. An Input/Output Analysis will be used in this stage to provide a system scan with details of the target system to ensure that the performance measurements are thorough. An Input/Output Analysis is composed of suppliers, inputs (information, equipments, material, etc.), value adding processes, outputs (product or services), customers, and desired outcomes. The mission and vision statements if not existing will be developed in this stage. Moreover, a SWOT Analysis (Strengths, Weaknesses, Opportunities, and Threats) should be developed in this stage to examine the organization's internal and external environments. Strengths and Weaknesses analyses focus on an organization's internal environment assessment, while Opportunities and Threats analyses focus on the organization's external environment.

\section{Define what we must excel}

In this stage, key performance areas (KPAs) will be developed. KPAs are the balanced scorecard's perspectives. However organization can modify these perspectives to fit the needs and the strategy of the organization. Note that some researchers might refer to KPAs as critical success factors, key success factors, critical result areas, and key result areas.

\section{Define how we know if we're successful}

In this stage, the metrics will be developed under each KPA. A set of 10-12 metrics is recommended for a unit within a larger organization, and a set of 15-20 metrics is recommended for the entire organization.

\section{Implementing the measurement system}

In this stage, a metric development matrix and a visibility board will be identified and developed. The metric development matrix will contain information about the metric specification; consisting of the metrics, the operational definitions and/or formulas, the purposes of the metrics, and the metric owners; the portrayal design :consisting of the portrayal frequencies, the types of data, and the portrayal tools; the data collection plan: consisting of the tracking tools, availability of the data, the data collection responsibilities, the data collection tools, the data collection frequencies; and utilization: consisting of the implementation dates and metric goals. The organization can also add other information that is useful to implement the performance measurement system to the metric development matrix. The metrics will then be portrayed on the visibility board.

\section{Utilize the measurement system}

After collecting and portraying data on the visibility board, the performance measurement system will be assessed and evaluated. The results can lead to many change initiatives in the organization. Next, the organization can review the impact of the initiatives. The organization can examine the performance measurement system, asking such things as whether the initiatives have led to good decision making, whether the performance 
measurement system has an impact on organizational performance, and whether it has been easy to execute. The organization can then identify and develop a new set of initiatives.

\section{Balanced Scorecard in Higher Education}

The balanced scorecard is widely used and accepted as a valuable tool in the industry sector. Recently, the balanced scorecard has also been used in not-for-profit organizations and academic institutions. One of the reasons that the balanced scorecard is not as widely used in this type of organization might be because of the perception on financial perspective. Financial perspective, as one of the components of the balanced scorecard might mislead one to think that the balanced scorecard is only useful for for-profit organizations. However, looking back at how the balanced scorecard was originated, the balanced scorecard was developed to replace the traditional measures which only focus on financial perspective. The concept of the balanced scorecard indicates that financial perspective is not the only important perspective of an organization and other performance perspectives should be taken into consideration. This also supports the goals of many academic institutions and units which financial perspective is not their main goal and most of the time is difficult to control.

Many published articles show the success of applying the balanced scorecard in higher education institutions. For example, a college in the United Kingdom used a balanced scorecard as a tool to manage quality of the college. ${ }^{9}$ Turku Polytechnic used a balanced scorecard to implement its strategies university-wide. ${ }^{6}$ The balanced scorecard enabled Turku Polytechnic with continuous improvement, helped redefine its existing strategy, and enhanced workers' understanding of objectives and strategy of the university. ${ }^{6}$ Chen, Yang, and Shiau ${ }^{10}$ used a balanced scorecard as a strategic management tool for Chin-Min Institute of Technology (CMIT), a private technology-centered university in Taiwan. With increasing competition in higher education in Taiwan and financial difficulty, the balanced scorecard helps CMIT increase the quality of its education and provides a competitive edge with other universities.

\section{Engineering Distance Learning Programs (EDLP) Background}

EDLP at Virginia Tech has provided post-baccalaureate education for working engineers and scientists for over twenty years. The programs are offered in various engineering disciplines include civil engineering, computer engineering, computer science, electrical engineering, engineering administration, industrial engineering, and mechanical engineering. The courses are available online and through interactive videoconferencing that delivers the courses to receive sites around the state and affiliated universities. There are seven distance learning programs under EDLP's umbrella which are (1) Center for Power Electronics System (CPES), (2) Commonwealth Graduate Engineering Program (CGEP), (3) Master's of Information Technology (MIT), (4) National Institute of Aerospace (NIA), (5) Master's of Science in Ocean Engineering (MSOE), (6) School of Biomedical Engineering and Sciences (SBES), and (7) Virginia Consortium of Engineering and Science Universities (VCES). Currently MSOE, and MIT are offered entirely online.

From the success of developing a balanced scorecard for CGEP, the Office of Distance Learning and Computing (ODLC) team, who overseas EDLP, took the initiative to develop a balanced scorecard for EDLP to monitor and manage the performance of all engineering distance learning programs. The balanced scorecard will indicate how well or how badly the programs have performed and whether or not it has developed in the right direction 
toward meeting its goals. EDLP also competes throughout the U.S. with other distance learning programs such as those at the University of Maryland that offers engineering degrees with a physical presence in Virginia, and the National Technological University (NTU) that offers over 1000 courses from 45 member universities. Not only will the balanced scorecard help EDLP compete effectively, it will also lead to many initiatives for continuous improvement of the programs.

\section{Development Process}

The ODLC team uses MSDP as a guideline to develop and implement the balanced scorecard for EDLP. The development was an expansion from CGEP's balanced scorecard. First the team defined ELDP's needs for a balanced scorecard. Next, the overall function of EDLP was reviewed and analyzed. The team identified the goals, mission, and vision of EDLP. Then the team conducted Input and Output, and SWOT analyses. Mission, Vision, and SWOT analysis of EDLP are presented below:

\section{Mission}

To provide high quality and accessible advanced engineering post-baccalaureate education through superior technological communications that meet with the industry trend.

\section{Vision}

To maintain and provide a leading post-baccalaureate distance learning engineering education in Virginia and beyond the state borders

\section{SWOT Analysis}

SWOT stands for strengths, weaknesses, opportunities, and threats. A SWOT Analysis is developed in this stage to examine EDLP's internal and external environments. Table 1 presents SWOT analysis for EDLP.

Table 1: SWOT analysis for EDLP.

\begin{tabular}{|c|c|}
\hline Strengths & Weaknesses \\
\hline $\begin{array}{l}\text { - Knowledge pool of faculty } \\
\text { - } \quad \text { Pool of facilities } \\
\text { - State of the art technology to } \\
\text { deliver courses } \\
\text { - } \quad \text { Ability to reach vast audiences }\end{array}$ & $\begin{array}{l}\text { - Barriers in communication } \\
\text { - Lack of exposure and difficulty } \\
\text { in publicity of the program } \\
\text { - Difficulty in transmission }\end{array}$ \\
\hline Opportunities & Threats \\
\hline $\begin{array}{l}\text { - Companies who want to increase } \\
\text { employees' knowledge and skills } \\
\text { - Increased industrial competition } \\
\text { - Working personnel who want to } \\
\text { improve their knowledge and skills }\end{array}$ & $\begin{array}{l}\text { - High competition from other } \\
\text { distance learning programs } \\
\text { - Students drop out because of } \\
\text { other commitments }\end{array}$ \\
\hline
\end{tabular}

Next key performance areas (KPAs) and metrics were developed. Brown ${ }^{11}$ suggested many important characteristics that metrics should (1) focus on measuring key variables instead of many unimportant ones, (2) be linked to the key success factors, (3), incorporate the past, the present, and the future of the organization, (4) be based on the needs of 
customers, shareholders, and stakeholders, (5) be adjusted to current strategy of the organization, and (6) have targets and goals established from research instead of arbitrary numbers. Four KPAs were identified for EDLP: (1) internal process, (2) customer satisfaction, (3) visibility, (4) financial viability. Next the metrics and its purposes, operational definition, upper and lower targets, data collection process, schedule for data collection, portrayal maintenance, and the owners were identified.

\section{Implementation}

The balanced scorecard is implemented. Data is identified, located, and collected. Then the metrics were revised. Some metrics were eliminated either because limited access to the data or information would not lead to changes or improvement (the team does not have a control over the issue). For example, course evaluation at the end of each semester was used as a tool to retrieve feedback from students on the course, the instructor, and delivery technology. Information from the course evaluation was used in three metrics: instructor effectiveness rating, VBS (Video Broadcasting Service) effectiveness, and student feedback. However, information on the course evaluation was confidential and the distance learning team was not able to retrieve the information after 3 years of negotiation. The distance learning team then developed its own survey that is scheduled to distribute every summer to students who took distance learning classes in the previous fall and spring. The team decided that the survey needed to be short (3 questions) and specific. The questions should be worded to retrieve information that the distance learning team would be able to use the information to improve the program. The survey was first distributed in summer 2006 with 13\% response rate.

As revision took place throughout 2 years after the balanced scorecard was first developed for EDLP, the team has implemented many changes to better monitor and improve EDLP's performance. The current metrics for EDLP is shown in Figure 2 along with the old metrics and the revision process. Important detail of each metrics is presented in Table 2. 


\begin{tabular}{|c|c|c|}
\hline Metrics & Revision & New Metrics \\
\hline \multicolumn{3}{|l|}{ KPA: Internal Process } \\
\hline $\begin{array}{l}\text { Frequency of core } \\
\text { courses offered }\end{array}$ & Revised & $\begin{array}{l}\text { Number of online } \\
\text { courses }\end{array}$ \\
\hline $\begin{array}{l}\text { Instructor } \\
\text { effectiveness rating }\end{array}$ & Eliminated & $\begin{array}{l}\text { Number of video- } \\
\text { conferencing courses }\end{array}$ \\
\hline VBS effectiveness & Eliminated & \\
\hline \multicolumn{3}{|c|}{ KPA: Customer Satisfaction } \\
\hline Student feedback & Revised & Student feedback \\
\hline Student attrition rate & $\rightarrow$ Eliminated & \\
\hline Faculty feedback & $\rightarrow$ Retained & Faculty feedback \\
\hline Employers' feedback & Eliminated & Number of graduates \\
\hline $\begin{array}{l}\text { Number of graduates } \\
\text { (drill-down by degree } \\
\text { completion time) }\end{array}$ & $\rightarrow$ Revised & $\begin{array}{l}\text { Average degree } \\
\text { completion time }\end{array}$ \\
\hline \multicolumn{3}{|l|}{ KPA: Visibility } \\
\hline $\begin{array}{l}\text { Number of hits on the } \\
\text { website }\end{array}$ & Retained & $\begin{array}{l}\rightarrow \text { Number of hits on the } \\
\text { website }\end{array}$ \\
\hline $\begin{array}{l}\text { Number of industrial } \\
\text { site visits, education } \\
\text { fairs, and open houses } \\
\text { attended }\end{array}$ & $\rightarrow$ Eliminated & \\
\hline $\begin{array}{l}\text { Percentage of } \\
\text { enrollment (drill-down } \\
\text { by visits and fairs) }\end{array}$ & Eliminated & \\
\hline $\begin{array}{l}\text { The total amount of } \\
\text { publicity }\end{array}$ & $\rightarrow$ Retained & $\begin{array}{l}\rightarrow \text { The total amount of } \\
\text { publicity }\end{array}$ \\
\hline \multicolumn{3}{|c|}{ KPA: Financial Viability } \\
\hline $\begin{array}{l}\text { Total funding of the } \\
\text { program (drill-down } \\
\text { by SCHEV and VT) }\end{array}$ & $\rightarrow$ Eliminated & \\
\hline $\begin{array}{l}\text { Enrollment } \\
\text { (drill-down by sites) }\end{array}$ & Retained & $\begin{array}{l}\text { Enrollment } \\
\text { (drill-down by } \\
\text { department) }\end{array}$ \\
\hline
\end{tabular}

Figure 2: Revision of EDLP's metrics. 


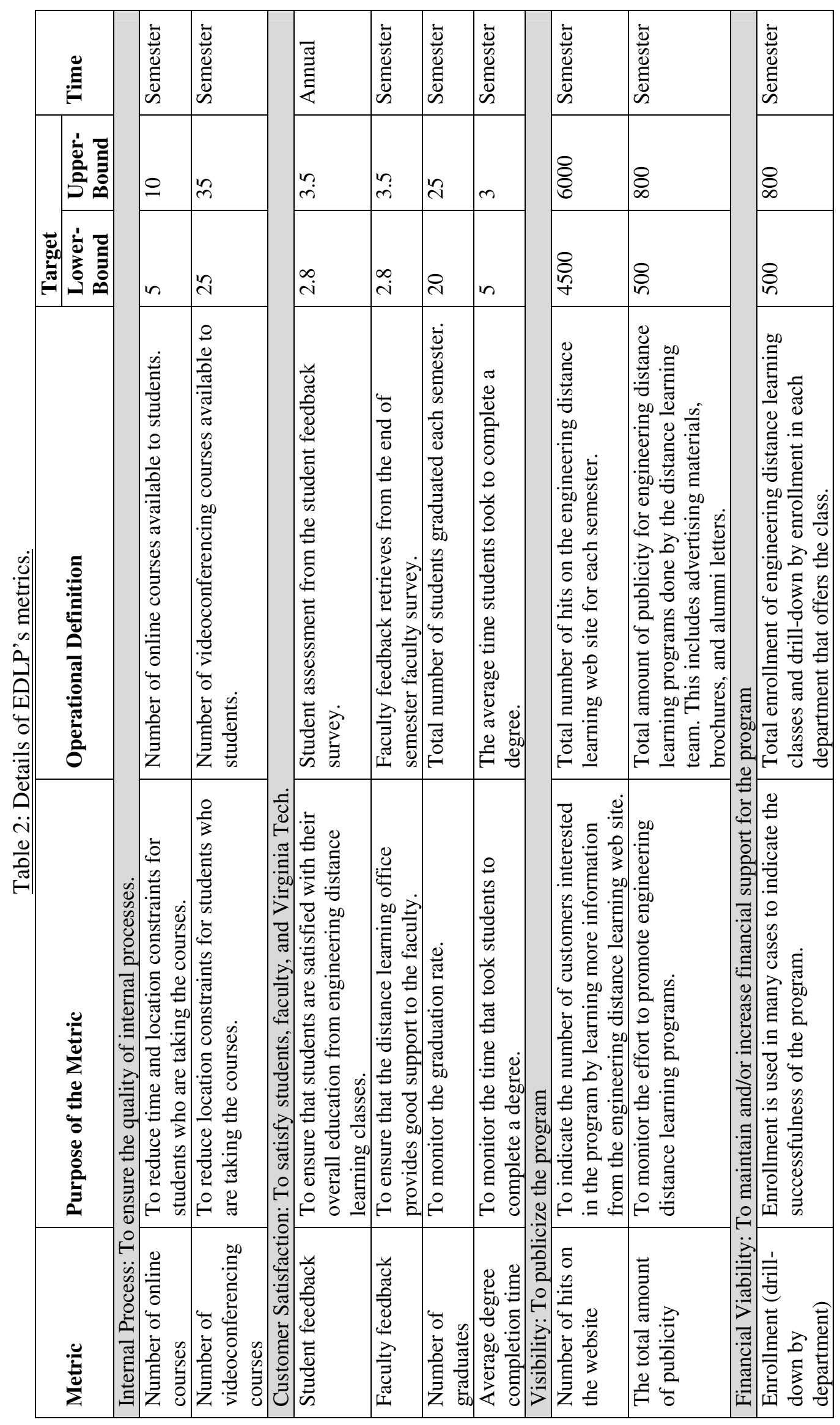

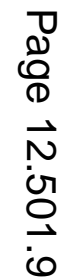


In the process of implementing the balanced scorecard for EDLP, the distance learning team searched for a software program to store and automatically display EDLP's data and performance. There are 10 main criteria that the distance learning team used to evaluate the software packages available in the market. These criteria are (1) cost, (2) user friendly, (3) number of users, (4) drill-down capability, (5) statistical analysis function, (6) web enabled function, (7) graphical presentation capability, (8) cause-effect relationship function, (9) platform transformation capability, and (10) Balanced Scorecard Collaborative certified (a company led by Kaplan and Norton). Two software programs were purchased one after another. The distance learning team tried to operate the balanced scorecard with these two programs for two years and felt that both programs did not meet our needs. Both programs lacked functions that the team felt were important in a balanced scorecard software. One program has poor display function, poor drill-down capability, and was not user friendly. Another program has poor platform transformation capability, poor drill-down capability, and poor display function. The team then decided to use a program developed by Sasima Thongsamak using Visual Basic for Applications (VBA) on MS-Excel and MS-Access platforms. ODLC is a trial unit for the program. The program meets the needs and provides necessary functions to automatically present information in graphs and reports. The program was developed with users-oriented concept, which makes it easy for users to use and maintain data. However, the program has some limited functions. Our next step is to expand the program capabilities and eliminate its limitation. Figure 4 and Figure 5 show the graph and a report created by the program.

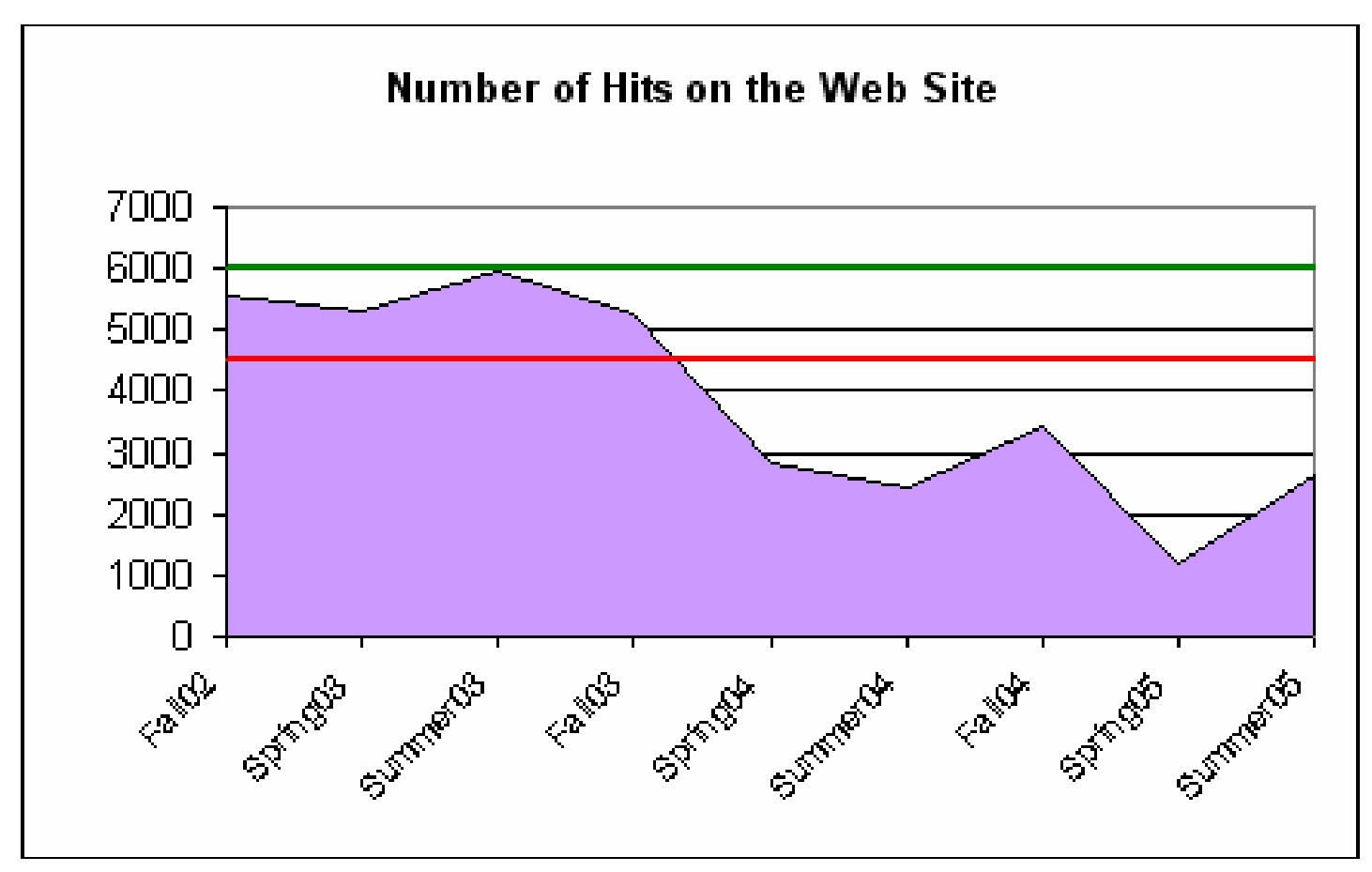

Figure 3: One of the display styles of the software program. 


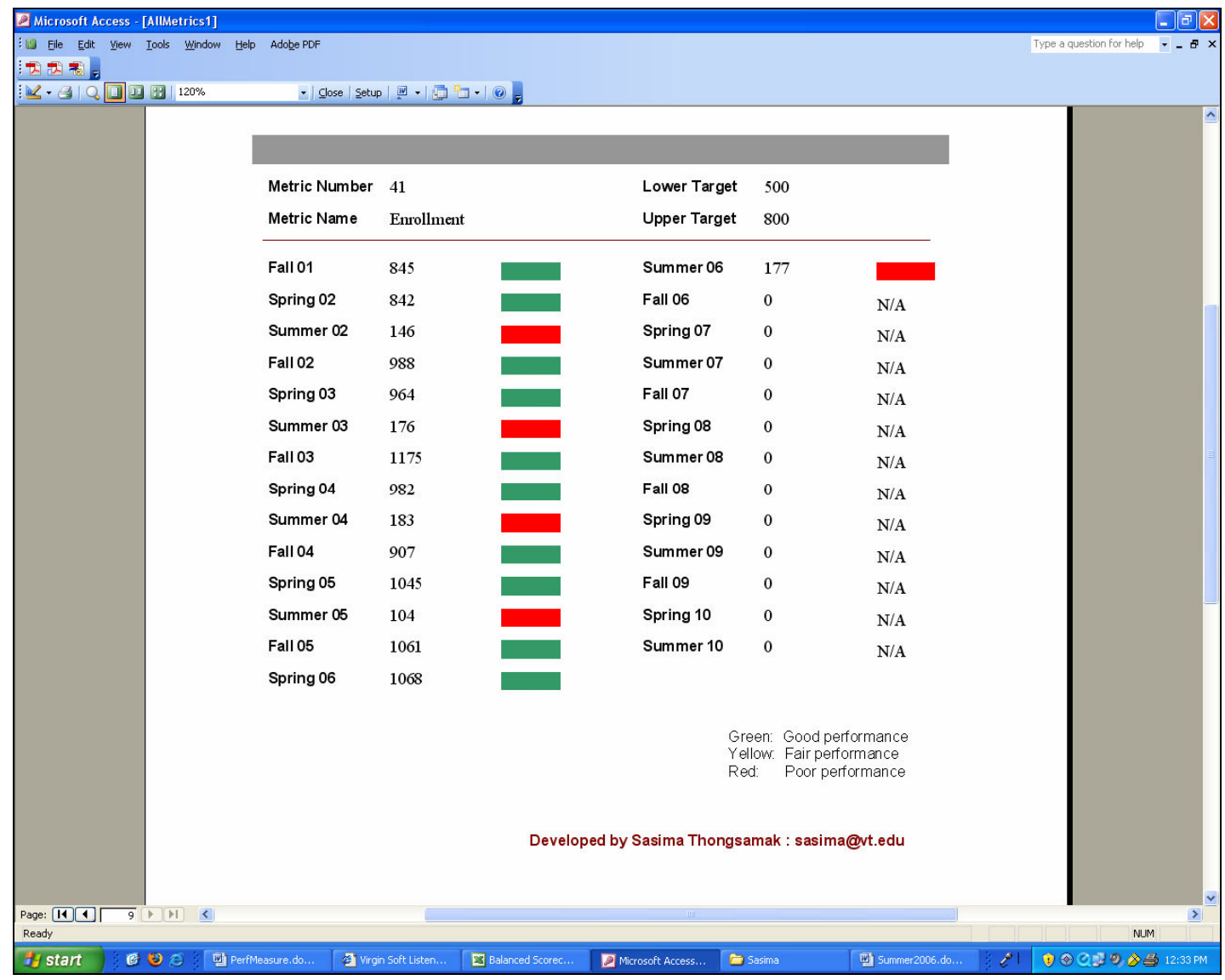

Figure 4: A report was created from the software program.

\section{Conclusions}

With the success of developing and implementing a balanced scorecard for CGEP, ODLC took the initiative to develop and implement a balanced scorecard for the EDLP. Student and faculty feedback surveys are developed resulting from the balance scorecard initiative. Student and faculty feedbacks are now able to be tracked in a timely manner, with full control of these surveys for the EDLP to administer and modify. The balance scorecard also enables the group to focus on the areas that are important to the improvement of EDLP. For example, ODLC used to track student attrition rates to identify reasons why students did not return to classes the next semester. It was found that most of the reasons students did not take classes the following semester were not related to performance of the programs but due to personal reasons such as family or work commitments. It was decided to eliminate this metric and focus on ones that matter to performance of EDLP.

Persistence and determination of the development team lead to the success of developing and implementing a balanced scorecard. However, this success cannot be accomplished without internal and management level commitments within the organization. Since the ODLC unit is rather small, internal and management level commitments were not difficult to secure, however, with bigger organizations, these might be harder to achieve.

Nevertheless, it is felt that internal and management level commitments are the key to the success of the development and implementation of a balanced scorecard. 


\section{Bibliography}

1. Kaplan, R.S, \& Norton, D.P. (1996). The balanced scorecard: Translating strategy into action. Boston, MA: Harvard Business School Press.

2. Amaratunga, D., Baldry, D., \& Sarshar, M. (2001). Process improvement through performance measurement: the balanced scorecard methodology. Work Study, 50(5), 179-188. Retrieved October 10, 2002 from Emerald Journals database.

3. Kaplan, R.S., \& Norton, D.P. (1998). The balanced scorecard-Measures that drive performance. Harvard Business Review on Measuring Corporate Performance 123145. Boston: Harvard Business School Press.

4. Parker, C. (2000). Performance measurement. Work Study, 49(2), 63-66. Retrieved October 10, 2002 from Emerald Journals database.

5. Stone, C. L. (1996). Analysing business performance: counting the "soft" issues. Leadership \& Organizational Development Journal,17(4), 21-28. Retrieved October 10, 2002 from Emerald Journals database.

6. Kettunen, J. (2005). Implementation of strategies in continuing education. International Journal of Educational Management, 19(3), 207-211. Retrieved June 26, 2006 from Emerald Journals database.

7. Rentes, A., \& Van Aken, E., (2000). Performance measurement system development process and case application. Enterprise Engineering Research Lab working paper, Course document, Blacksburg, VA: Virginia Polytechnic Institute and State University.

8. Van Aken, E.M., \& Coleman, G.D. (2001). Using measurement to define and improve value-added, invited paper and presentation. The XIIth World productivity Congress. Hong Kong and Beijing: Word Confederation of Productivity Science.

9. Cullen, Joyce, Hassall, \& Broadbent (2003). Quality in higher education: from monitoring to management. Quality Assurance in Education, 11(1), 5-14. Retrieved June 26, 2006 from Emerald Journals database.

10. Chen, S., Yang, C., \& Shiau, J. (2006). The application of balanced scorecard in the performance evaluation of higher education. The TQM Magazine, 18(2), 190-205. Retrieved June 26, 2006 from Emerald Journals database.

11. Brown, M.G. (1996). Keeping score: Using the right metrics to drive world-class performance. New York: Quality Resources. 